\title{
The improvement of hypoxia correlates with neuroanatomic and developmental outcomes: Comparison of midterm outcomes in infants with transposition of the great arteries or single-ventricle physiology
}

Keijiro Ibuki, MD, ${ }^{\mathrm{a}}$ Kazuhiro Watanabe, MD, ${ }^{\mathrm{a}}$ Naoki Yoshimura, MD, ${ }^{\mathrm{b}}$ Tachiyo Kakimoto, MA, Mie Matsui, MD, ${ }^{\mathrm{d}}$ Taketoshi Yoshida, MD, ${ }^{\mathrm{c}}$ Hideki Origasa, $\mathrm{PhD},{ }^{\mathrm{e}}$ and Fukiko Ichida, MD ${ }^{\mathrm{a}}$

Objectives: We performed a prospective longitudinal study of the neuroanatomic and developmental changes in infants with transposition of the great arteries (TGA) or single-ventricle (SV) physiology to identify variables in anatomic development of the brain associated with functional impairment.

Methods: Thirty-three infants with congenital heart defects, 23 with SV and 10 with TGA, were studied at around 1 year old (time 1) and 3 years old (time 2 ) by magnetic resonance imaging of the brain. Neurodevelomental assessment was performed at the same time.

\begin{abstract}
Results: The whole and frontal lobe volumes were significantly reduced in both groups at time 1 compared with normal control subjects $(P<.01)$. However, by time 2 whole and frontal brain volumes were normal in the TGA group but remained significantly smaller $(P<.01)$ in the $\mathrm{SV}$ group. In agreement with these findings, the mental development index (MDI) was lower $(P<.05)$ at time 1 in both groups but improved to normal levels at time 2 in the TGA group. In the SV group, both MDI and the psychomotor development index (PDI) were significantly decreased at both time 1 and time $2(P<.01)$. These patients continued to experience hypoxia, and multivariate analysis revealed that functional oxygen saturation was significantly associated with PDI. Further, the PDI score correlated with whole and regional brain volumes $(P<.05)$.
\end{abstract}

Conclusions: Neuroanatomic and developmental outcomes improve progressively in infants with TGA, unlike those with SV physiology. Impaired cerebral circulation and hypoxia may have significant effects on brain growth and development in infants with critical congenital heart disease. (J Thorac Cardiovasc Surg 2012;143:1077-85)

Despite the dramatically reduced mortality owing to recent advances in medical and surgical techniques, ${ }^{1}$ considerable neurologic and developmental sequelae are observed after heart surgery in infants with complex congenital heart disease (CHD). ${ }^{2-4}$ The developing nervous system is influenced by a complex interaction of perioperative factors in infants with $\mathrm{CHD}$, and the impact of perioperative management on neurodevelopmental outcomes has been reported. ${ }^{5,6} \mathrm{~A}$ high prevalence of neuroanatomic and functional abnormalities is observed in newborns with $\mathrm{CHD}^{7,8}$ In newborns with transposition

\footnotetext{
From the Departments of Pediatrics, ${ }^{\mathrm{a}}$ Cardiothoracic Surgery, ${ }^{\mathrm{b}}$ Neonatology, ${ }^{\mathrm{c}}$ and Psychology, ${ }^{\mathrm{d}}$ and the Division of Biostatistics, ${ }^{\mathrm{e}}$ University of Toyama, Toyama, Japan.

This study was supported by grants from Core Research for Evolutional Science and Technology (Japan Science and Technology Agency), Japanese Study of Cognitive Function after Open Heart Surgery in Pediatric Patients (Ministry of Health, Labour and Welfare), and JSPS Asian Core Program(Japanese Society for the Promotion of Science).

Disclosures: Authors have nothing to disclose with regard to commercial support. Received for publication Nov 10, 2010; revisions received Aug 5, 2011; accepted for publication Aug 26, 2011; available ahead of print Oct 3, 2011.

Address for reprints: Fukiko Ichida, MD, Department of Pediatrics, University of Toyama, 2630 Sugitani, Toyama, Toyama, 930-0194 Japan (E-mail: fukiko@ med.u-toyama.ac.jp).

$0022-5223 / \$ 36.00$

Copyright (c) 2012 by The American Association for Thoracic Surgery

doi:10.1016/j.jtcvs.2011.08.042
}

of the great arteries (TGA) or single-ventricle (SV) physiology, altered brain metabolism and microstructure are observed shortly after birth, even in the absence of visible injury on magnetic resonance imaging (MRI). ${ }^{9}$ However, the long-term effects of altered brain metabolism and microstructure on neurodevelopmental outcome have not been described in patients with critical CHD.

$\mathrm{We}^{10}$ previously reported that preoperative hypoxia is associated with decreased frontal gray matter volume, and frontal gray matter volume correlated weakly with psychomotor development index scores (PDI) in infants with critical CHD, such as TGA and SV, several months after surgery. The aim of this study was to compare longitudinal neuroanatomic and developmental outcomes between infants with TGA and those with SV physiology at around 1 year and 3 years of age. We hypothesized that infants with TGA, whose oxygenation improved after early surgical correction, would have better neuroanatomic and developmental outcome than those with SV physiology who continued to have hypoxia.

\section{METHODS \\ Patients}

We performed a prospective longitudinal study of 33 neonates with TGA or SV physiology born in or transferred to the Toyama University 


\section{Abbreviations and Acronyms \\ 3D-MRI $=3$-dimensional magnetic resonance imaging \\ BSID-II = Bayley Scales of Infant Development-Second Edition \\ CHD = congenital heart disease \\ MDI = mental development index \\ MRI = magnetic resonance imaging \\ PDI = psychomotor development index \\ $\mathrm{SpO}_{2}=$ functional oxygen saturation \\ $\mathrm{SV}=$ single ventricle \\ TGA $=$ transposition of the great arteries \\ WISC-III $=$ Wechsler Intelligence Scale for Children-Third Edition \\ WPPSI $=$ Wechsler Preschool and Primary State of Intelligence}

Hospital between July 2003 and April 2009. Neonates were excluded if their gestational age was less than 36 weeks or if they had genetic or malformation syndromes. Brain volumes were measured using 3-dimensional MRI (3D-MRI) at 2 time points, with the first scan at around 1 year old (15.4 \pm 6.2 months of age) and the second scan at around 3 years old $(38.8 \pm 17.4$ months of age). The 3D-MRI study was performed at least 6 months after the latest heart surgery in each patient.

Neurodevelopmental assessment was performed by a pediatric psychologist (K.T.) during the same period as the MRI scan, on average 3 weeks after the scan. The first assessment was performed using the Bayley Scales of Infant Development-Second Edition (BSID-II), which includes 2 scores: the mental development index (MDI) and the PDI. The second assessment was performed using the BSID-II, as well as the Wechsler Preschool and Primary Scale of Intelligence (WPPSI) or the Weshsler Intelligence Scale for Children-Third Edition (WISC-III), depending on the patient's age. If assessment was performed by WPPSI and WISC-III, we substituted the BSID-II PDI score at the second time point. Preoperative clinical data were prospectively collected from the medical records and reviewed by pediatric cardiologists who were blinded to the 3D-MRI findings.

Forty-six control infants and children (age, 2-117 months; mean, $31.7 \pm$ 28.3 months) were recruited from the children of Toyama University Hospital staff and siblings of ambulatory patients in the brain volumetric study. They were born at term gestational age without any complicated perinatal courses. Their body weight and body length were within normal range, and they all had normal neurologic development. These data were used to make the best fitting model lines for normal regional brain volumes (whole brain, frontal lobe, and temporal lobe). These models were used to compare the brain volumes of CHD patients with the volumes of normal control subjects at the same age. The age distribution was not significantly different between the study patients and normal control subjects.

The Research Ethics Committee of Toyama University Hospital approved the study. After the study purpose and all procedures were fully explained, written informed consent was obtained from parents.

\section{MRI Scan Acquisition and Image Processing}

Before MRI, all patients and normal control subjects were sedated with oral monosodium trichorethyl phosphate syrup $(0.51 .0 \mathrm{~mL} / \mathrm{kg})$. MRI scans were performed with a 1.5-T Magnetom Vision scanner (Siemens, Erlangen, Germany), as previously described. ${ }^{11}$ In short, axial images were obtained with a fast low-angle shot gradient refocused 3-dimensional sequence with the following parameters: repetition time $=35 \mathrm{~ms}$, echo time $=6 \mathrm{~ms}$, flip angle $=35^{\circ}$, nex $=1$. The obtained images were T1weighted with a field of view of $256 \mathrm{~mm}$ and a $256 \times 256$ matrix size, and the entire scan was obtained in 15 minutes. The thickness of each slice was $1.0 \mathrm{~mm}$, and 140 to 170 contiguous slices were obtained in each case. After each acquisition, volumetry of whole brain, temporal lobes, and frontal lobes were undertaken using a LINUX workstation. All image processing was performed with a semiautomated software package. Whole brain volumes were derived from the entire cerebral cortex, including frontal, temporal, parietal, and occipital lobes. Manual delineation of cerebral hemispheres was based on standard guidelines ${ }^{12,13}$ and frontal and temporal lobar volumes were calculated by previously described procedures. $^{10,14}$

\section{Reliability of Regional Volumetric Measurements}

Five images, selected randomly, were quantified twice by a rater (K.I) to determine intrarater reliability. Intraclass correlations for whole brain, frontal lobe, and temporal lobe were all greater than 0.80 for intrarater reliability. The rater (K.I.) then completed the analysis on the remaining scans.

\section{Statistical Analyses}

The relationships between whole, frontal, and temporal brain volumes and age in normal control subjects were derived using the curve-fitting approach by linear regression with fractional polynomials of age as the covariates. In infants with TGA or SV physiology, the 1-sample $t$ test was used to examine the relationship to population norms for the neurodevelopmental assessment scores and brain volumes. The TGA and SV groups were compared at each time point using the 2-sample $t$ test. Risk factors for the reduced regional brain volume and neurodevelopmental score were assessed by multiple regression analysis. We performed multivariate analyses with variables that included the following: birth weight and head circumference at birth; functional oxygen saturation $\left(\mathrm{SpO}_{2}\right)$ on admission to the neonatal intensive care unit; need for artificial ventilation during the neonatal period (neonatal variables); body weight, body length, and $\mathrm{SpO}_{2}$ at the time of MRI (examination variables); diagnoses of asplenia, hypoplastic left heart syndrome, and total anomalous pulmonary venous return (diagnostic variables); and whether they underwent a Blalock-Taussig shunt, operation during the neonatal period, or required extracorporeal circulation during the neonate period; extracorporeal circulation time; and aortic crossclamp time (interventional variables). The statistical computations were performed with SPSS version 15.0 (SPSS, Inc, Cary, NC).

\section{RESULTS \\ Patients Characteristics}

Clinical characteristics of the patients are shown in Table 1. Thirty-three patients with critical CHD were enrolled in this study, including 10 infants with TGA and 23 with SV physiology. In the TGA group, 9 infants had TGA (type 1) and 1 had double-outlet right ventricle, the so called Taussig-Bing anomaly. The SV group included 3 infants with hypoplastic left heart syndrome, 11 with SV, 5 with tricuspid valve atresia, 2 with double-outlet right ventricle, 1 with mitral valve atresia, and 1 with pulmonary valve atresia. The oxygen saturation was significantly lower in the SV group both at time 1 and at time $2(P<.01)$ (Table 1$)$. Body weight at birth was significantly less in the SV group than in the TGA group. Extracorporeal circulation in the neonatal period was significantly higher more commonly in the TGA group 
TABLE 1. Patient characteristics and operative variables

\begin{tabular}{|c|c|c|c|c|}
\hline Variables & TGA group $(n=10)$ & SV group $(n=23)$ & & $P$ value \\
\hline \multicolumn{5}{|l|}{ Patient-related variables } \\
\hline Gender (male/female) & $5 / 5$ & $9 / 14$ & & NS \\
\hline Gestational age (wk) & $39.0 \pm 1.2$ & $38.7 \pm 1.9$ & & NS \\
\hline Birth weight (g) & $3115.9 \pm 409.5$ & $2630.0 \pm 524.7$ & & $P<.01$ \\
\hline Birth head circumference $(\mathrm{cm})$ & $33.5 \pm 0.9$ & $32.2 \pm 2.6$ & & NS \\
\hline \multicolumn{5}{|l|}{ Variables at examination } \\
\hline \multicolumn{5}{|l|}{ Age at MRI (mo) } \\
\hline Time 1 & $13.4 \pm 4.0$ & $15.5 \pm 6.5$ & & NS \\
\hline Time 2 & $44.3 \pm 18.8$ & $37.1 \pm 16.9$ & & NS \\
\hline \multicolumn{5}{|l|}{ Oxygen saturation $(\%)$} \\
\hline Time 1 & $98.0 \pm 1.2$ & $81.4 \pm 4.7$ & & $P<.01$ \\
\hline Time 2 & $98.1 \pm 0.6$ & $93.2 \pm 4.7$ & & $P<.01$ \\
\hline \multicolumn{5}{|l|}{ Body length ( $\mathrm{Z}$ ) } \\
\hline Time 1 & $-0.92 \pm 1.26$ & $-1.86 \pm 1.60$ & & NS \\
\hline Time 2 & $-0.69 \pm 1.52$ & $-1.66 \pm 1.50$ & & NS \\
\hline \multicolumn{5}{|l|}{ Body weight (Z) } \\
\hline Time 1 & $-0.27 \pm 1.53$ & $-1.41 \pm 1.20$ & & NS \\
\hline Time 2 & $-0.63 \pm 1.24$ & $-1.33 \pm 1.10$ & & NS \\
\hline \multicolumn{5}{|l|}{ Operation in neonatal period } \\
\hline \multicolumn{5}{|l|}{ Palliative operation } \\
\hline BT shunt & & $11(48 \%)$ & & \\
\hline $\mathrm{PAB}$ & & $5(22 \%)$ & & \\
\hline Norwood & & $3(13 \%)$ & & \\
\hline TAPVC repair & & $3(13 \%)$ & & \\
\hline Arterial switch operation & $10(100 \%)$ & & & \\
\hline ECC in neonatal period & $10(100 \%)$ & $7(30 \%)$ & & $P<.01$ \\
\hline PVL in neonates & 0 & 0 & & \\
\hline \multicolumn{5}{|l|}{ Complication } \\
\hline LV outflow tract obstruction & & $5(22 \%)$ & & \\
\hline TAPVC & & $9(39 \%)$ & & \\
\hline Asplenia & & $8(35 \%)$ & & \\
\hline Severe valvular regurgitation & & $5(22 \%)$ & & \\
\hline Latest surgical procedures in SV & & Time 1 & Time 2 & \\
\hline Palliative operation & 98 & & & \\
\hline Stage 1 (Norwood, BT, PAB) & & $6(0 / 4 / 2)$ & & \\
\hline Stage 2 (Glenn, Glenn + DKS) & & $14(11 / 3)$ & $7(6 / 1)$ & \\
\hline Total correction (TCPC) & & & 15 & \\
\hline \multicolumn{5}{|l|}{ Operative variables in operation } \\
\hline \multicolumn{5}{|l|}{ ECC time (min) } \\
\hline Time 1 & $268 \pm 24$ & $161 \pm 122$ & & $P<.05$ \\
\hline Time 2 & $268 \pm 24$ & $407 \pm 226$ & & NS \\
\hline \multicolumn{5}{|l|}{ ACC time (min) } \\
\hline Time 1 & $170 \pm 33$ & $47 \pm 59$ & & $P<.01$ \\
\hline Time 2 & $170 \pm 33$ & $89 \pm 84$ & & $P<.01$ \\
\hline
\end{tabular}

Body weight and height at examination were expressed as Z-scores. TGA, Transposition of the great arteries; $S V$, single-ventricle; $N S$, not significant; $M R I$, magnetic resonance imaging; $Z$, Z scores; $B T$, Blalock-Taussig shunt; $P A B$, pulmonary artery banding; $T A P V C$, total anomalous pulmonary venous connection; $E C C$, extracorporeal circulation; $P V L$, periventricular leukomalacia; $L V$, left ventricular; $D K S$, Damus-Kaye-Stansel operation; $T C P C$, total cavopulmonary connection; $A C C$, aortic crossclamp. CC and ACC shows total time of multiple operations until times 1 and 2.

than the SV group. Total times of extracorporeal circulation at time 1 and aortic crossclamp both at time 1 and time 2 were significantly longer in the TGA group than the SV group. Other variables including gender, gestational age, head circumference at birth, age, and body weight at MRI examination were not significantly different between the 2 groups. All patients underwent cerebral ultrasonography on admission to the neonatal intensive care unit and at discharge, and periventricular leukomalacia was not diagnosed in any patients in either group or during the neonatal period. All of the TGA patients underwent total correction during the neonatal period, whereas 22 of the SV patients 

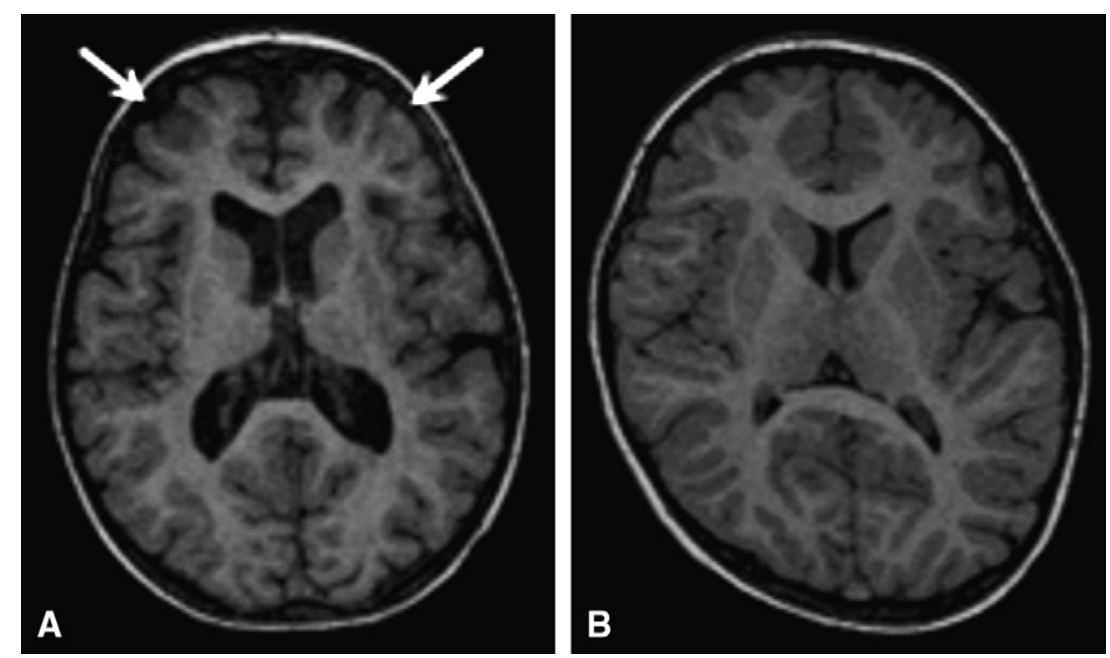

FIGURE 1. Brain MRIs of patients with TGA or SV physiology at time 2. The cerebral cortex of a 27-month-old female patient with SV physiology (A) appeared more atrophic than that of a 30-month-old male patient with TGA (B) The white arrows indicate the atrophic frontal lobe of the patient with SV physiology. MRI, Magnetic resonance image; TGA, transposition of the great arteries; SV, single-ventricle.

underwent palliative operation including Blalock-Taussig shunt, pulmonary artery banding, Norwood procedure, and repair of total anomalous pulmonary venous connection. Cardiopulmonary bypass was performed in all patients in the TGA group and in 7 patients in the SV group during the neonatal period (Table 1). Neuroexaminations, performed by a neuropediatrician, revealed no significant abnormalities in any of the patients except in 1 floppy infant in the SV group. Clinical review of the anatomic MRI scans at times 1 and 2 by a neuroradiologist (K.N.) did not identify signs of infarction, hemorrhage, or other anatomic anomalies in any patients.

\section{Volumetry of the Brain Using 3D-MRI}

Figure 1 shows representative MRIs of patients in the TGA and SV groups at time 2. Decreases in whole brain volume, especially frontal gray matter, are apparent in the SV patient compared with the age-matched TGA patient. Atrophy of the cerebral cortex, especially the frontal lobe, was more apparent in the patient with SV physiology than the TGA patient.

The distribution by age of the global volumes of whole brain, frontal lobe, and temporal lobe for each of the patients, as well as the best fitting models for normal controls, is shown in Figure 2. As described previously, ${ }^{11}$ brain volumes increased rapidly during the first 2 years after birth and then started to plateau at around 24 months of age (Figure 2).

\section{Comparison of Quantitative-3D MRI Data and Neurodevelopmental Scores Between Patients and Normal Controls}

Comparisons of brain volumes and neurodevelopmental assessment scores between the patients in each group and normal controls are shown in Table 2. In the TGA group, whole brain and frontal lobe volumes were decreased $(P<.01$ and $P<.05$, respectively) at time 1 but were normal by time 2: temporal volumes were normal at both time points. In contrast, in the SV group, whole and frontal brain volumes were significantly smaller at both time points $(P<.01)$, whereas temporal lobe volumes at time 1 were moderately decreased $(P<.05)$ and did not improve at time $2(P<.01)$. Neurodevelopmental assessment scores were concordant with the MRI data. In the TGA group, MDI scores were significantly lower at time $1(P<.05)$ but improved to normal at time 2: PDI scores were normal at both time points. In the SV group, MDI and PDI scores were significantly lower at both time points $(P<.01)$ (Table 2).

\section{Comparison of Quantitative-3D MRI and Neurodevelopmental Scores Between the TGA and SV Physiology Groups}

At time 1, whole and regional brain volumes were not different between the 2 groups (Figure 3, A). However, at time 2 , whole brain volumes were significantly smaller in the SV physiology group than the TGA group $(P<.05)$ (Figure 3, $A)$. Frontal lobe volumes tended to be smaller in the SV group than the TGA group at both time points, but the difference was not significant (Figure 3, A). Temporal lobe volumes were not different at either time (Figure 3, $A$ ). Figure 3, $B$, shows the comparison of neurodevelopmental assessment scores between the TGA and SV groups. At time 1, MDI is not significantly different between the 2 groups, but at time 2 it is significantly lower in the SV group $(P<.05)$. In contrast, PDI scores are significantly lower in the SV group than the TGA group at both times (Figure 3, B). 

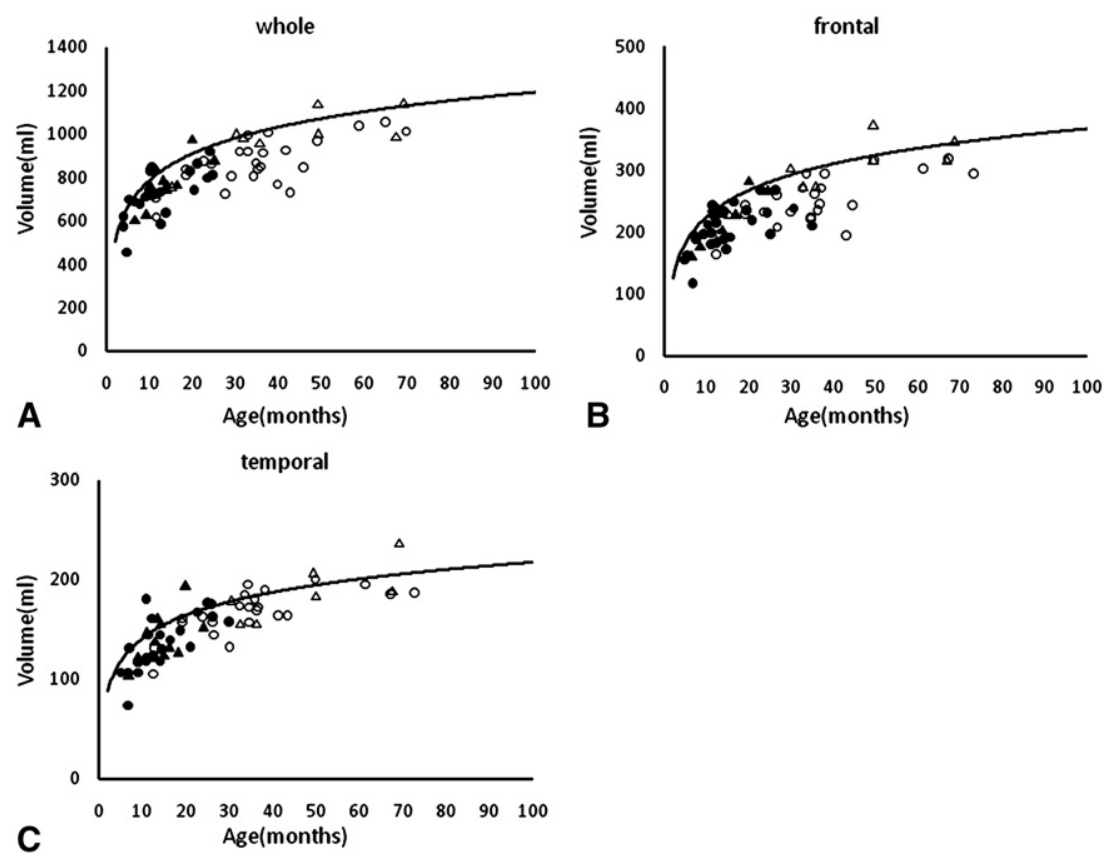

FIGURE 2. The distribution by age of the volumes of whole brain (A), frontal lobe (B), temporal lobe (C). The line shows best fitting models for normal control subjects. For whole brain, frontal lobe and temporal lobe, the best fitting models for normal controls were as follows: whole brain $=175.93 \ln ($ age $)+$ $384.03\left(P<.01, R^{2}=0.83\right)$; frontal lobe $=61.90 \ln ($ age $)+82.09\left(P<.01, R^{2}=0.81\right)$; temporal lobe $=32.96 \ln ($ age $)+65.59\left(P<.01, R^{2}=069\right)$. TGA at time 1 is indicated by closed triangles and time 2 by open triangles. SV physiology at time 1 is indicated by closed circles and time 2 by open circles. TGA, Transposition of the great arteries; $S V$, single-ventricle.

\section{Correlation Between Regional Brain Volumes and Neurodevelopmental Assessment}

Analysis of the relationship between whole and regional brain volumes by 3D-MRI and neurodevelopmental

TABLE 2. Brain volumes and neurodevelopmental assessment comparison with normal variance

\begin{tabular}{ccccc}
\hline & $\begin{array}{c}\text { TGA group } \\
(\mathbf{n}=\mathbf{1 0})\end{array}$ & $\boldsymbol{P}$ value & $\begin{array}{c}\text { SV group } \\
(\mathbf{n}=\mathbf{2 3})\end{array}$ & $\boldsymbol{P}$ value \\
\hline Brain volumes $($ mean $\pm S D)$ & & & \\
Time 1 & & & & \\
Whole & $0.92 \pm 0.08$ & $P<.01$ & $0.88 \pm 0.11$ & $P<.01$ \\
Frontal & $0.93 \pm 0.08$ & $P<.05$ & $0.88 \pm 0.12$ & $P<.01$ \\
Temporal & $0.99 \pm 0.14$ & NS & $0.93 \pm 0.13$ & $P<.05$ \\
Time 2 & & & & \\
Whole & $0.95 \pm 0.08$ & NS & $0.86 \pm 0.08$ & $P<.01$ \\
Frontal & $0.98 \pm 0.09$ & NS & $0.86 \pm 0.10$ & $P<.01$ \\
Temporal & $0.99 \pm 0.11$ & NS & $0.94 \pm 0.10$ & $P<.01$ \\
& & & & \\
Neurodevelopmental assessment (mean $\pm S D)$ & & \\
Time 1 & & & & \\
MDI & $89.7 \pm 10.1$ & $P<.05$ & $82.4 \pm 15.5$ & $P<.01$ \\
PDI & $94.6 \pm 13.9$ & NS & $75.9 \pm 18.5$ & $P<.01$ \\
Time 2 & & & & \\
MDI & $95.9 \pm 14.0$ & NS & $85.8 \pm 17.8$ & $P<.01$ \\
PDI & $97.3 \pm 13.4$ & NS & $79.3 \pm 20.9$ & $P<.01$ \\
\hline
\end{tabular}

The $P$ value means comparison between patients and normal variance. $S D$, Standard deviation; $M D I$, mental development index; $P D I$, psychomotor development index; other abbreviations are the same as in Table 1. Brain volumes are expressed as ratio to normals. assessment scores showed that MDI was associated with frontal lobe volume and PDI was associated with whole and regional brain volumes. Furthermore, whole brain and frontal lobe volumes were moderately associated with $\mathrm{SpO}_{2}$ (Table 3).

\section{Risk Factors for Abnormal Neurodevelopment and Brain Volumes}

Multivariate risk factor analysis showed that $\mathrm{SpO}_{2}$ was significantly associated with PDI at both time 1 and time $2(P<.01$ and $P<.05$, respectively). Further, surgery during the neonatal period was moderately associated with PDI at time $1(P<.05)$. None of the variables was associated with MDI at both time periods. Blalock-Taussig shunt was associated with whole brain at time $2(P<.05)$. Asplenia was moderately associated with whole brain volume at time 1 $(P<.05)$. Other variables, such as birth weight, head circumference at birth, $\mathrm{SpO}_{2}$ at admission, using a respirator or undergoing extracorporeal circulation during the neonatal period, and body weight at examination did not correlate with either brain volume or neurodevelopmental scores (Table 4).

\section{DISCUSSION}

\section{Decreased Brain Volume and Fetal Circulation}

In this study we show that at about 1 year of age whole brain volumes in patients with TGA and whole and regional 

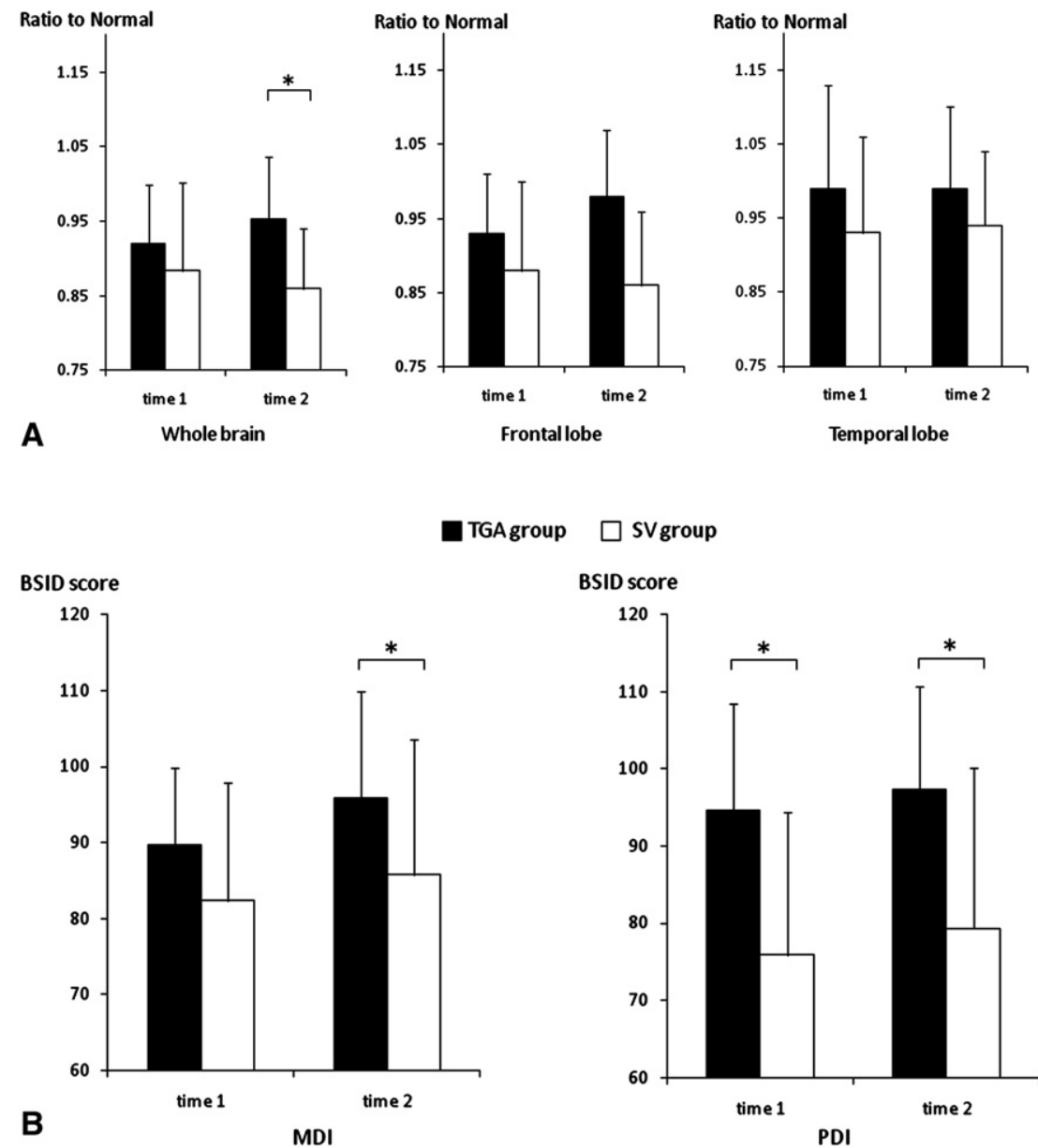

TGAgroup

SVgroup
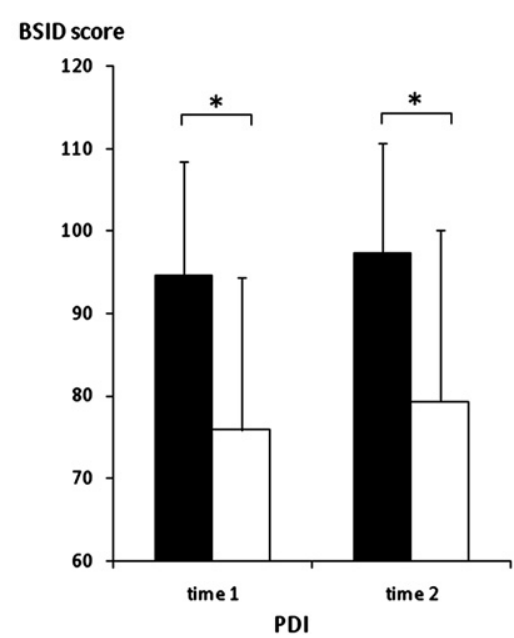

FIGURE 3. A, Comparison of regional brain volume between the TGA and SV groups at time 1 and time 2 . The vertical axis means the ratio to normal approximate value. At time 1, whole and regional brain volumes are not different between the 2 groups. At time 2, whole brain and frontal lobe volumes are significantly smaller in the SV group than the TGA group. There are no statistically significant differences in temporal lobe volume. $* P<.05$. TGA, Transposition of the great arteries; $S V$, single-ventricle. B, Comparison of neurodevelopmental assessment scores between the TGA and SV groups at time 1 and time 2. MDI at time 1 is not different between the 2 groups, but MDI at time 2 in the SV group is significantly lower than in the TGA group. PDI at time 1 and time 2 is significantly lower in the SV group than the TGA group. ${ }^{*} P<.05$. TGA, Transposition of the great arteries; $S V$, single-ventricle; $B S I D$, Bayley Scales of Infant Development; $M D I$, mental development index; PDI, psychomotor development index.

brain volumes in patients with SV physiology are smaller than in normal controls, consistent with previous reports of brain abnormalities in fetuses and infants with CHD. More than half of newborns with CHD have impaired cerebral metabolism preoperatively, ${ }^{8,9,16}$ and cerebral blood flow abnormalities have been identified in newborns with hypoplastic left heart syndrome or dextro-TGA using MRI. ${ }^{17}$ In neonates with preoperative TGA, hypoxic brain injury has been observed by MRI and ultrasound. . $^{8,16,18,19}$ This impaired neuroanatomic development in infants with CHD most likely begins in the fetus and is probably caused by abnormal cerebrovascular blood flow dynamics during the fetal period inasmuch as abnormalities of cerebral blood flow, cerebral vascular resistance, brain metabolism, and reduced brain volume have been observed by ultrasound, MRI, and magnetic resonance spectroscopic images. ${ }^{15,20,21}$

After birth, low cerebral blood flow and oxygen delivery are common in infants with complex CHD and are related to white matter injury. ${ }^{16}$ Low diastolic blood pressure is often seen, especially in infants receiving prostaglandin $E_{1}$, as well as after systemic-pulmonary shunt operations, and may correlate with white matter injury and global cerebral ischemia. ${ }^{15}$ Our data indicate that children undergoing Blalock-Taussig shunt are at higher risk of having decreased frontal lobe volumes during the first 3 years of life. Abnormal cerebral hemodynamic circulation may correlate with abnormal brain growth. 
TABLE 3. Correlation between neurodevelopmental assessment scores and regional brain volumes

\begin{tabular}{|c|c|c|c|}
\hline & Whole brain & Frontal lobe & Temporal lobe \\
\hline \multicolumn{4}{|c|}{ Neurodevelopmental assessment } \\
\hline MDI & NS & $P<.05$ & NS \\
\hline PDI & $P<.05$ & $P<.05$ & $P<.05$ \\
\hline $\mathrm{SpO}_{2}$ & $P<.05$ & $P<.05$ & NS \\
\hline
\end{tabular}

Moreover, this study indicates that brain volumes normalize in TGA patients over time but do not in SV physiology patients. This observation correlates with the fact that infants with TGA undergo arterial switch operations, which correct cerebral hemodynamics. In normal children, the most rapid growth of the whole brain, including the frontal and temporal lobes, is seen during the first 2 years after birth. ${ }^{15}$ Therefore, we hypothesize that the normalization of cerebral blood flow and correction of hypoxia play an important role in the brain growth in infants with CHD, especially during the first 2 years. In the TGA group, the Z-value

TABLE 4. Variables analyzed for association with PDI and whole brain volume

\begin{tabular}{|c|c|c|c|c|}
\hline \multirow[b]{2}{*}{ PDI } & \multicolumn{2}{|c|}{ Time 1} & \multicolumn{2}{|c|}{ Time 2} \\
\hline & $\begin{array}{c}\text { Regression } \\
\text { coefficient }\end{array}$ & $\begin{array}{c}P \\
\text { value }\end{array}$ & $\begin{array}{c}\text { Regression } \\
\text { coefficient }\end{array}$ & $\begin{array}{c}P \\
\text { value } \\
\end{array}$ \\
\hline \multicolumn{5}{|l|}{ Variables at examination } \\
\hline BW at examination $(\mathrm{Z})$ & 0.139 & .464 & 0.234 & .229 \\
\hline $\mathrm{SpO}_{2}$ at examination & 0.537 & .005 & 0.41 & .034 \\
\hline \multicolumn{5}{|l|}{ Diagnosis } \\
\hline Asplenia & 0.055 & .761 & -0.108 & .566 \\
\hline HLHS & 0.024 & .896 & 0.018 & .933 \\
\hline \multicolumn{5}{|l|}{ Intervention } \\
\hline BT shunt & -0.156 & .488 & -0.227 & .275 \\
\hline $\begin{array}{l}\text { Operation during neonatal } \\
\text { period }\end{array}$ & -0.403 & .030 & -0.278 & .132 \\
\hline ECC during neonatal period & 0.287 & .293 & -0.017 & .930 \\
\hline ECC (total time) & 0.020 & .913 & -0.322 & .089 \\
\hline ACC (total time) & 0.269 & .257 & -0.018 & .925 \\
\hline \multicolumn{5}{|l|}{ Whole brain volume } \\
\hline \multicolumn{5}{|l|}{ Variables at examination } \\
\hline BW at examination $(\mathrm{Z})$ & 0.063 & .756 & -0.180 & .367 \\
\hline $\mathrm{SpO}_{2}$ at examination & 0.248 & .187 & 0.070 & .742 \\
\hline \multicolumn{5}{|l|}{ Diagnosis } \\
\hline Asplenia & -0.459 & .016 & -0.235 & .232 \\
\hline HLHS & -0.019 & .918 & 0.196 & .324 \\
\hline \multicolumn{5}{|l|}{ Intervention } \\
\hline BT shunt & -0.085 & .659 & -0.382 & .049 \\
\hline $\begin{array}{l}\text { Operation during neonatal } \\
\text { period }\end{array}$ & 0.131 & .476 & 0.180 & .345 \\
\hline ECC during neonatal period & 0.116 & .528 & 0.274 & .158 \\
\hline ECC (total time) & -0.074 & .686 & -0.193 & .359 \\
\hline ACC (total time) & -0.035 & .851 & 0.094 & .621 \\
\hline
\end{tabular}

$\mathrm{Z,Z}$ scores; body weight and height at examination were expressed as Z-scores. $B W$, body weight; $H L H S$, hypoplastic left heart syndrome. Other abbreviations are the same as in Tables 1 and 2. of body length did not change from time 1 to time 2, whereas the $\mathrm{Z}$-value of body weight decreased from time 1 to time 2 (Table 1). Therefore, the differences in brain growth cannot simply be explained by better somatic growth in the TGA patients.

\section{Decreased Neurodevelopmental Assessment Scores}

Two measures of neurodevelopment, MDI and PDI, indicate impaired neurodevelopment in patients with SV physiology throughout the study period, whereas for patients with TGA only, MDI scores were lower at time 1 and these normalized by the second assessment. Consistent with previous reports, ${ }^{22}$ motor skills, as assessed by PDI, are more significantly impaired than cognitive function (MDI scores) in the SV patients after cardiac surgery. In preterm infants, brain injury caused by hypoxia has been demonstrated to increase the risk of adverse neurodevelopmental outcomes, ${ }^{23}$ and Petit and associates ${ }^{24}$ reported that in TGA infants, preoperative brain injury is related to severity and duration of exposure to hypoxemia. By multiregression analysis, our data indicate that $\mathrm{SpO}_{2}$ influences PDI score, suggesting improvement of hypoxia during the early neonatal period in patients with TGA results in PDI score normalization even by 1 year of age. Thus, the correlation between restored cerebral hemodynamic circulation and improved of hypoxia may play an important role in both normal neuroanatomic and normal neurodevelopment in infants with CHD who have undergone surgery.

\section{Correlation Between 3D-MRI Brain Volume and Neurodevelopmental Score}

Our data show that neurodevelopment in CHD patients is positively associated with brain volume. Further, MDI is correlated with frontal lobe volume, PDI with whole and regional brain volumes, and whole and frontal brain volumes are positively associated with $\mathrm{SpO}_{2}$ at the time of MRI study. These data support our hypothesis that correction of cerebral hemodynamics and hypoxia results in the improvement in neuroanatomic and developmental growth in infants with critical CHD.

In SV patients, frontal lobe volume is decreased more significantly than temporal lobe volume. We assume that the frontal lobe growth tends to be more affected by hemodynamic conditions and hypoxia than the temporal lobe. There are important areas, such as the primary motor and premotor areas, in the frontal lobe that are strongly associated with motor function. Of note, in this study, frontal lobe volume correlates with oxygen saturation. Therefore, we assume that the correction of hypoxia may affect frontal lobe volume predominantly and further result in improved PDI scores. The maturation or myelination of the frontal lobe is slower than that of other regions of the brain, ${ }^{25}$ which may result in more prominent effects in the frontal lobe during stress, such as restricted blood flow or maternal smoking 
during pregnancy. ${ }^{26}$ Reduced frontal lobe volumes have also been shown in children with attention deficit-hyperactivity disorder, aged 5 to 18 years, compared with age- and sex-matched control subjects. ${ }^{27}$

Although we observed neuroanatomic and developmental improvements in TGA patients, there are some reports of behavioral, cognitive, and learning disorders in school-aged patients with TGA. Bellinger and coworkers ${ }^{28}$ reported significantly lower scores for motor skills, visual-spatial skills, and cognition in 8-year-old children with TGA than in the normal population. Therefore, longer functional assessment should be undertaken in our study population.

\section{Study limitation}

The major limitation is the moderate sample size of 33 patients, including only 10 in the TGA group, which may have influenced the statistical analyses of differences in brain volumes and neurodevelopmental scores between the 2 groups. Another limitation to this study is a lack of multiple age-matched controls. We compared brain volumes with those derived from analysis of multiple normal individuals over a large age range. The data in normal infants were fixed and derived from a large database. ${ }^{10} \mathrm{Al}$ though the study was designed to compare individuals at 1 and 3 years of age, the actual ages varied somewhat inasmuch as we waited to perform the MRI examination and developmental assessments until at least 6 months after the latest surgical procedure to exclude any direct influence of the procedure. Our data are also limited because we do not have 3D-MRI brain volume data for neonates, although there are some reports describing reduced brain volumes and neonatal brain injury in fetuses with CHD. ${ }^{9,20}$

\section{CONCLUSIONS}

We conclude that medium-term neuroanatomic and developmental outcomes improve progressively in infants with TGA by 3 years of age, unlike those with SV physiology. Low PDI scores are associated with low $\mathrm{SpO}_{2}$ at MRI examination, and decreased brain volumes are associated with reduced PDI score. Thus, impaired cerebral circulation and hypoxia may have significant effects on brain growth and development. This study encourages larger scale and longer follow-up to clarify the significance of hypoxemia to impaired neuroanatomic development with functional outcome in the CHD population.

We acknowledge Jun Nakazawa, Junko Matsuzawa, Kazuhisa Hongo, Warren Bilker, Ruben C. Gur, Hikaru Seto, Hisao Nishijo, Michio Suzuki, Chiaki Tanaka, Kazuyoshi Saito, Sayaka Ozawa, Keiich Hirono, Kyo Noguchi, Yoshihiro Oshima, Toshio Miyawaki, Toshikatsu Yagihara, and all members of Japanese Study of Cognitive Function after Open Heart Surgery in Pediatric Patients for their pertinent suggestions and cooperation. We appreciate Neil Bowles for his excellent assistance.

\section{References}

1. Welke KF, Shen I, Ungerleider RM. Current assessment of mortality rates in congenital cardiac surgery. Ann Thorac Surg. 2006;82:164-70; discussion 170-61.

2. Ballweg JA, Wernovsky G, Gaynor JW. Neurodevelopmental outcomes following congenital heart surgery. Pediatr Cardiol. 2007;28:126-33.

3. Dittrich H, Buhrer C, Grimmer I, Dittrich S, Abdul-Khaliq H, Lange PE. Neurodevelopment at 1 year of age in infants with congenital heart disease. Heart. 2003;89:436-41.

4. Tabbutt S, Nord AS, Jarvik GP, Bernbaum J, Wernovsky G, Gerdes M, et al. Neurodevelopmental outcomes after staged palliation for hypoplastic left heart syndrome. Pediatrics. 2008;121:476-83.

5. Newburger JW, Jonas RA, Wernovsky G, Wypij D, Hickey PR, Kuban KC, et al. A comparison of the perioperative neurologic effects of hypothermic circulatory arrest versus low-flow cardiopulmonary bypass in infant heart surgery. $N$ Engl J Med. 1993;329:1057-64.

6. Wypij D, Jonas RA, Bellinger DC, Del Nido PJ, Mayer JE Jr, Bacha EA, et al. The effect of hematocrit during hypothermic cardiopulmonary bypass in infant heart surgery: results from the combined Boston hematocrit trials. J Thorac Cardiovasc Surg. 2008;135:355-60.

7. Limperopoulos C, Majnemer A, Rosenblatt B, Shevell MI, Rohlicek C, Tchervenkov C, et al. Association between electroencephalographic findings and neurologic status in infants with congenital heart defects. J Child Neurol. 2001;16:471-6.

8. Miller SP, McQuillen PS, Vigneron DB, Glidden DV, Barkovich AJ, Ferriero DM, et al. Preoperative brain injury in newborns with transposition of the great arteries. Ann Thorac Surg. 2004;77:1698-706.

9. Miller SP, McQuillen PS, Hamrick S, Xu D, Glidden DV, Charlton N, et al. Abnormal brain development in newborns with congenital heart disease. $N$ Engl J Med. 2007;357:1928-38.

10. Watanabe K, Matsui M, Matsuzawa J, Tanaka C, Noguchi K, Yoshimura N, et al. Impaired neuroanatomic development in infants with congenital heart disease. $J$ Thorac Cardiovasc Surg. 2009; 137:146-53.

11. Matsuzawa J, Matsui M, Konishi T, Noguchi K, Gur RC, Bilker W, et al. Age-related volumetric changes of brain gray and white matter in healthy infants and children. Cereb Cortex. 2001;11:335-42.

12. Kohn MI, Tanna NK, Herman GT, Resnick SM, Mozley PD, Gur RE, et al. Analysis of brain and cerebrospinal fluid volumes with MR imaging. Part i. Methods, reliability, and validation. Radiology. 1991;178:115-22.

13. Mozley PD, Gur RE, Resnick SM, Shtasel DL, Richards J, Kohn M, et al. Magnetic resonance imaging in schizophrenia: relationship with clinical measures. Schizophr Res. 1994;12:195-203.

14. Turetsky B, Cowell PE, Gur RC, Grossman RI, Shtasel DL, Gur RE. Frontal and temporal lobe brain volumes in schizophrenia. Relationship to symptoms and clinical subtype. Arch Gen Psychiatry. 1995;52:1061-70.

15. Donofrio MT, Bremer YA, Schieken RM, Gennings C, Morton LD, Eidem BW, et al. Autoregulation of cerebral blood flow in fetuses with congenital heart disease: the brain sparing effect. Pediatr Cardiol. 2003;24:436-43.

16. Mahle WT, Tavani F, Zimmerman RA, Nicolson SC, Galli KK, Gaynor JW, et al. An MRI study of neurological injury before and after congenital heart surgery. Circulation. 2002;106:I109-14.

17. Licht DJ, Wang J, Silvestre DW, Nicolson SC, Montenegro LM, Wernovsky G, et al. Preoperative cerebral blood flow is diminished in neonates with severe congenital heart defects. J Thorac Cardiovasc Surg. 2004;128:841-9.

18. Te Pas AB, van Wezel-Meijler G, Bokenkamp-Gramann R, Walther FJ. Preoperative cranial ultrasound findings in infants with major congenital heart disease. Acta Paediatr. 2005;94:1597-603.

19. Krull F, Latta K, Hoyer PF, Ziemer G, Kallfelz HC. Cerebral ultrasonography before and after cardiac surgery in infants. Pediatr Cardiol. 1994;15: 159-62.

20. Limperopoulos C, Tworetzky W, McElhinney DB, Newburger JW, Brown DW, Robertson RL Jr, et al. Brain volume and metabolism in fetuses with congenital heart disease: evaluation with quantitative magnetic resonance imaging and spectroscopy. Circulation. 2010;121:26-33.

21. Kaltman JR, Di H, Tian Z, Rychik J. Impact of congenital heart disease on cerebrovascular blood flow dynamics in the fetus. Ultrasound Obstet Gynecol. 2005; 25:32-6.

22. Gaynor JW, Wernovsky G, Jarvik GP, Bernbaum J, Gerdes M, Zackai E, et al. Patient characteristics are important determinants of neurodevelopmental outcome at one year of age after neonatal and infant cardiac surgery. J Thorac Cardiovasc Surg. 2007;133:1344-53. 1353.e1-3. 
23. Bass JL, Corwin M, Gozal D, Moore C, Nishida H, Parker S, et al. The effect of chronic or intermittent hypoxia on cognition in childhood: a review of the evidence. Pediatrics. 2004;114:805-16.

24. Petit CJ, Rome JJ, Wernovsky G, Mason SE, Shera DM, Nicolson SC, et al. Preoperative brain injury in transposition of the great arteries is associated with oxygenation and time to surgery, not balloon atrial septostomy. Circulation. 2009; 119:709-16.

25. Barkovich AJ, Kjos BO, Jackson DE Jr, Norman D. Normal maturation of the neonatal and infant brain: MR imaging at 1.5 t. Radiology. 1988;166: 173-80.
26. Ekblad M, Korkeila J, Parkkola R, Lapinleimu H, Haataja L, Lehtonen L. Maternal smoking during pregnancy and regional brain volumes in preterm infants. $J$ Pediatr. 2010;156:185-90. e181.

27. Sowell ER, Thompson PM, Welcome SE, Henkenius AL, Toga AW, Peterson BS Cortical abnormalities in children and adolescents with attention-deficit hyperactivity disorder. Lancet. 2003;362:1699-707.

28. Bellinger DC, Wypij D, duPlessis AJ, Rappaport LA, Jonas RA, Wernovsky G, et al. Neurodevelopmental status at eight years in children with dextrotransposition of the great arteries: the Boston circulatory arrest trial. $J$ Thorac Cardiovasc Surg. 2003;126:1385-96. 